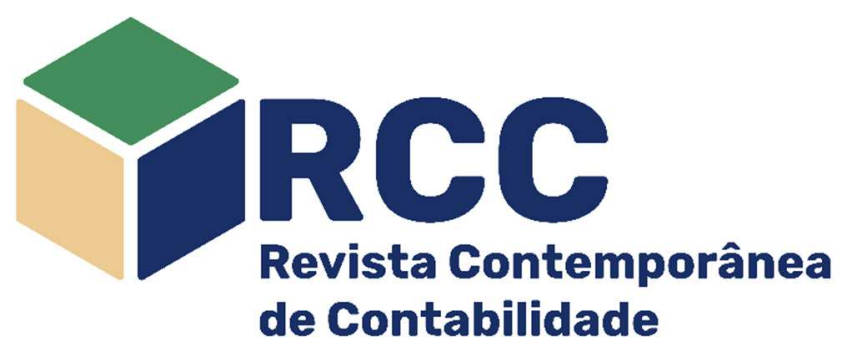

\title{
Multinacionalidade, ativos intangíveis e agressividade fiscal
}

\author{
Multinationality, intangible assets and tax aggressiveness \\ Multinacionalidad, activos intangibles y agresividad fiscal
}

Ana Paula Araújo Lima Mestre em Contabilidade pela FUCAPE Business School Consultora Tributária, Fortaleza/CE, Brasil anapaulaufc@yahoo.com.br http://orcid.org/0000-0003-2520-5101 (0)

Silvania Neris Nossa Doutora em Contabilidade e Administração na FUCAPE Business School Professora da FUCAPE Business School, Vitória/ES, Brasil silvanianossa@fucape.br https://orcid.org/0000-0001-8087-109X (0)

\author{
Valcemiro Nossa* \\ Doutor em Controladoria e Contabilidade (USP) \\ Professor do Programa de Pós-Graduação em Ciências Contábeis e \\ Administração da FUCAPE Business School, Vitória/ES, Brasil \\ valcemiro@fucape.br \\ https://orcid.org/0000-0001-8091-2744 (10) \\ Nadia Cardoso Moreira \\ Doutora em Contabilidade e Administração na \\ FUCAPE Business School \\ Professora da FUCAPE Business School, Vitória/ES, Brasil \\ nadiacmoreira@fucape.br \\ https://orcid.org/0000-0002-9085-6595 (c)
}

\section{Resumo}

Endereço do contato principal para correspondência* Av. Fernando Ferrari, 1358, Boa Vista, CEP: 29075-505 - Vitória/ES, Brasil

Atualmente, a agressividade fiscal e a multinacionalidade tem sido temas recorrentes em pesquisas internacionais na área contábil. O objetivo deste estudo é analisar como a agressividade tributária (BTD ou TTVA) é afetada pela multinacionalidade, considerando o nível de ativos intangíveis das empresas listadas na B3. Para isso, foi realizada uma pesquisa quantitativa a partir da análise de regressão, em que se testaram duas proxies de agressividade fiscal (BTD e TTVA). Os resultados permitem inferir que a presença de multinacionalidade está relacionada a menores níveis de agressividade fiscal, em média. No entanto, a presença de multinacionalidade relacionada a maiores níveis de ativos intangíveis gera maiores níveis de agressividade fiscal.

Palavras-chave: Agressividade fiscal; Multinacionalidade; Ativos intangíveis

\section{Abstract}

Currently, tax aggressiveness and multinationality have been recurring themes in international accounting research. This study aims to analyze how tax aggressiveness (BTD or VATR) is affected by multinationality, considering the level of intangible assets of companies listed on B3 (Brazil stock exchange). For this, a quantitative research was carried out from the regression analysis, where two proxies of tax aggressiveness where tested (BTD and TTVA). The results allow us to infer that, on average, the presence of multinationality is related to lower levels of tax aggressiveness. However, the presence of multinationality, related to higher levels of intangible assets generates higher levels of tax aggressiveness.

Keywords: Tax aggressiveness; Multinationality; Intangible assets

\section{Resumen}

La agresividad fiscal y la multinacionalidad han sido temas recurrentes en la investigación internacional en el ámbito contable. Este Estudio tiene como objetivo analizar cómo la agresividad fiscal (BTD o TTVA) se ve afectada por la multinacionalidad considerando el nivel de activos intangibles de las empresas que cotizan en B3. Para ello, se realizó una investigación cuantitativa con el análisis de regresión, utilizando dos proxies de agresividad (BTD y TTVA). Los resultados permiten inferir que la presencia de multinacionalidad se relaciona con menores niveles de agresividad fiscal, en promedio. Sin embargo, la presencia de multinacionalidad relacionada con mayores niveles de activos intangibles genera mayores niveles de agresividad fiscal.

Palabras clave: Agresividad fiscal; Multinacionalidad; Activos intangibles 


\section{Introdução}

Os dois temas discutidos na literatura contábil internacional são a agressividade tributária e a multinacionalidade das empresas, isso porque há indícios de que a tributação influencia efetivamente nos negócios, principalmente, quando há alteração da localização das empresas que visam a redução dos tributos (Blouin, 2012; Silva \& Martinez, 2016; Schanz, Dinkel \& Keller, 2017; Lawless, McCoy, Morgenroth \& O"Toole, 2018; Ramos \& Martinez, 2018; Pieretti \& Pulina, 2020; Johannesen, Torslov, \& Wier, 2020; Oguttu \& KayisKumar, 2020; Choi, Furusawa \& Ishikawa, 2020; Goyvaerts \& Roggeman, 2020; Mardan \& Stimmelmayr, 2020, Merlo, Riedel \& Wamser, 2020; Nerudova, Solilova, Litzman \& Janský, 2020; Akhtar, Akhtar, John \& Wong, 2019).

Os resultados de pesquisas desenvolvidas em diferentes países mostram que as empresas podem se deslocar de um ambiente para outro em busca de menores custos tributários, e inclusive, as empresas podem se transferir até de país (Schanz et al., 2017; Lawless et al., 2018; Pieretti \& Pulina, 2020; Johannesen et al., 2020).

Ao explorar os caminhos tomados pelos empresários para mitigar custos tributários, Nerudova et al. (2020) se propuseram a identificar os canais de transferência de lucros. Eles concluíram que os lucros das empresas analisadas geralmente são deslocados pela movimentação das receitas, dos custos operacionais e do uso de canais de dívida. Os investimentos feitos em paraísos fiscais exigem menos receita operacional para obter resultados mais altos. Barrios e D'Andria (2020) concluíram, após a análise de dados a nível mundial, que aqueles setores que realizam mais transferências de lucros reduziram seu custo médio de capital, e com isso atraíram mais investimentos, quando comparados aos demais setores menos capazes de se esquivar dos impostos. Eles também concluíram que os ativos intangíveis se mostram relacionados à transferência de lucros (Barrios \& D'Andria, 2020).

O nível de ativos intangíveis é um fator economicamente relevante devido a sua alta subjetividade de mensuração e sua capacidade de gerar benefícios fiscais decorrentes do aproveitamento das amortizações, o que traz vantagem competitiva às organizações e pode ter relação direta com o grau de agressividade fiscal das empresas (Oliveira \& Beuren, 2003; Perez \& Famá, 2006; Kaplan \& Norton, 2009; Taylor \& Richardson, 2015; Silva, 2016; Barrios \& D'Andria, 2020).

No cenário internacional, os estudos preliminares trazem evidências da relação entre a multinacionalidade e o grau de agressividade fiscal das empresas. Nesses estudos, eles analisam empesas de diferentes países que exploram as lacunas existentes na legislação e a ausência de regras claras para regulação do comércio internacional. As empresas exploram tais lacunas com a finalidade de planejamento tributário, sendo que os aumentos são expressivos nos resultados associados à multinacionalidade das empresas (Blouin, 2012; Zucman, 2014; Taylor \& Richardson, 2015; Picciotto, 2018; Barrios \& D'Andria, 2020; Oguttu \& Kayis-Kumar 2020, Goyvaerts \& Roggeman, 2020; Mardan \& Stimmelmayr, 2020; Merlo et al., 2020).

Nos últimos anos, os ativos intangíveis também foram reconhecidos como mecanismos que os gestores podem lançar mão em direção à agressividade tributária. O uso de ativos intangíveis ocorre devido às oportunidades de planejamento tributário trazidas pela dedutibilidade da amortização e à dificuldade de verificação desses benefícios fiscais pelas autoridades fiscais (Markusen, 1995; Markham, 2005; Perez \& Famá, 2006; Blouin, 2012; Ocean, 2017; Hamamura, 2018; Silva, 2016; Maluf \& Asano, 2019; Barrios \& D'Andria, 2020).

Em um contexto nacional, ainda há evidências empíricas de que a agressividade fiscal é determinada pelas controladoras nos grupos empresariais, que buscam estratégias de transferência de renda intragrupo para redução da tributação (Ferreira, Martinez, Costa, \& Passamani, 2012; Martinez \& Dalfior, 2015).

Neste estudo, pretende-se olhar para uma lacuna ainda não observada na literatura, que é verificar como a agressividade tributária é afetada pela multinacionalidade, considerando o nível de ativos intangíveis de cada empresa. No que se refere a agressividade tributária, neste estudo a novidade está em se trabalhar com a Book Tax Diferences (BTD) e Taxa de Tributação sobre o Valor Adicionado (TTVA). A BTD olha para a diferença entre o valor contábil e fiscal para mensurar a agressividade tributária. A multinacionalidade nesse estudo é mensurada de 3 formas: 1) quando há controle substancial da empresa brasileira por empresa estrangeira; 2) quando há subsidiária em país estrangeiro; 3) quando há investimentos estrangeiros diretos. A proposta é verificar se a cultura de se transferir de um mercado para outro, em busca de menores custos, também se mantém quando o investidor é uma empresa estrangeira.

A justificativa para a realização desta pesquisa deve-se aos resultados da mesma, na direção de que há oportunidades de planejamento tributário gerados pelo aproveitamento de benefícios fiscais, operações entre as multinacionais, bem como por meio do aproveitamento das amortizações dos ativos intangíveis. Outra justificativa se fundamenta nos resultados do estudo de Johannesen et al. (2020), que analisaram dados de 210.000 corporações em 142 diferentes países e verificaram que a evasão fiscal por empresas multinacionais é mais provável em países menos desenvolvidos. Ressalta-se a ausência de trabalhos anteriores que investiguem esta temática. No cenário internacional não existem trabalhos que investigam o contexto explorado nesta pesquisa, mas existem estudos que relacionam a multinacionalidade aos preços de transferência (Blouin, 2012; Silva \& Martinez, 2016; Schanz et al., 2017, Lawless et al., 2018; Ramos \& Martinez, 2018; Pieretti \&Pulina, 2020; Johannesen et al., 2020; Oguttu \& Kayis-Kumar, 2020; Choi et al., 
2020; Goyvaerts \& Roggeman, 2020; Mardan \& Stimmelmayr, 2020; Merlo et al., 2020; Nerudova et al. 2020; Akhtar et al., 2019). Além disso, há também estudos que relacionam a multinacionalidade e ativos intangíveis aos preços de transferência (Taylor \& Richardson, 2015, Barrios \& D'Andria, 2020). Diante do exposto, esta pesquisa preenche uma lacuna ainda não observada empiricamente, já que o mercado brasileiro se trata de um mercado em desenvolvimento sobre o qual ainda não se tem registros de uma pesquisa com esta proposta.

Portanto, a ideia para a realização deste estudo partiu do trabalho desenvolvido por Taylor e Richardson (2015) no mercado americano sobre preço de transferência, que é considerado um tipo de agressividade fiscal. As particularidades encontradas no cenário brasileiro, como a alta carga tributária, legislação complexa com constantes alterações e guerra fiscal entre estados são mecanismos que podem influenciar na agressividade fiscal, e por isso, buscou-se analisar se a multinacionalidade e os ativos intangíveis podem ser fatores que incentivam a implantação de práticas tributariamente agressivas no mercado nacional (Silva, 2016).

Para a realização deste estudo foi desenvolvida uma pesquisa empírica, quantitativa, com a utilização da análise de regressão para o teste de hipóteses. Os dados financeiros estudados foram obtidos por meio da base de dados da Economatica ${ }^{\circledR}$ e coletados nos formulários de referência disponíveis no sítio da B3, alguns dados foram coletados nas Demonstrações do Valor Adicionado (DVA) no sítio das empresas. Foram coletados dados referentes às companhias do mercado brasileiro listadas na B3 no período de 2010 a 2017.

Neste estudo, a agressividade fiscal é a variável explicada mensurada pelo BTD e a TTVA, que seguem os estudos de Frank, Lynch e Rego (2009) e Silva (2016), respectivamente. A multinacionalidade é mensurada por meio de três variáveis dummy, criadas a partir da definição trazida por Markusen (1995): 1) variável dummy indica a presença de controle substancial de uma empresa estrangeira; 2) variável dummy indica a existência de subsidiária em um país estrangeiro; 3) variável dummy indica a existência de investimentos estrangeiros diretos. O nível dos ativos intangíveis foi mensurado pelo valor total de ativos intangíveis dividido pelo ativo total, conforme utilizado por Chen, Chen, Cheng e Shevlin (2010).

Esta pesquisa contribui com a literatura nacional e traz evidências empíricas sobre a relação da agressividade fiscal e as estratégias tributárias de income shifting (transferência de renda) adotadas pelas empresas brasileiras, utilizadas como ferramenta de planejamento tributário. Outra contribuição desta pesquisa está em verificar como a presença de multinacionalidade, considerando o nível de ativo intangível, pode afetar a agressividade fiscal das empresas, tanto na diferença entre o valor contábil e fiscal, quanto no imposto pago em relação ao valor adicionado. Estes resultados trazem evidências ainda não observadas nacionalmente e nem internacionalmente, e podem ajudar os stakeholders na tomada de decisões relativas ao tema. Este estudo traz ainda evidências que corroboram para a identificação de outros perfis e características de empresas brasileiras tributariamente agressivas, conforme sugerido por Martinez e Dalfior (2016), e pode ajudar os entes públicos com informações empíricas que permitem mitigar os impactos da sonegação fiscal aos cofres públicos.

Os resultados encontrados neste estudo são de que a presença de multinacionalidade reduz, em média, o nível de agressividade fiscal nas empresas, mas na presença de multinacionalidade, na medida em que aumentam os níveis de ativos intangíveis observa-se o aumento nos níveis de agressividade fiscal.

\section{Revisão da Literatura}

\subsection{Agressividade Fiscal}

A agressividade fiscal é uma característica presente em grandes empresas que buscam estratégias para redução da carga tributária, ela ocorre por meio da alocação da tributação entre os membros de um grupo econômico, localizados em diferentes jurisdições, que manipula ou controla de forma intencional os preços praticados intragrupo para reduzir a renda tributável (Chen et al., 2010; Blouin, 2012; Taylor \& Richardson, 2015; Silva \& Martinez, 2016; Schanz et al., 2017; Lawless et al., 2018; Ramos \& Martinez, 2018; Pieretti \& Pulina, 2020; Johannesen et al., 2020; Oguttu \& Kayis-Kumar , 2020; Choi et al., 2020; Goyvaerts \& Roggeman, 2020; Mardan \& Stimmelmayr, 2020; Merlo et al., 2020; Nerudova et al., 2020; Akhtar et al., 2019).

A agressividade fiscal é também inferida pela falta de mecanismos de controle do monitoramento de transações intragrupo, práticas relacionadas à manipulação dos lucros que objetivam apenas a redução da carga tributária, que podem trazer impactos diretos na evasão fiscal aos cofres públicos (Eccles, 1985; Emmanuel \& Mehafdi, 1994; Colbert \& Spicer, 1995; Taylor \& Richardson, 2015; Ramos \& Martinez, 2018; Rodrigues, Melo, \& Paulo, 2019). Nerudova et al. (2020) se propuseram a identificar os canais de transferência de lucros a partir dos dados de Estados Membros da União Europeia. Eles concluíram que os lucros das empresas analisadas geralmente são deslocados pela movimentação das receitas, custos operacionais, e o uso de canais de dívida. Eles concluíram ainda, que grupos vinculados a paraísos fiscais pagam menos impostos. Adicionalmente, eles observaram que os investimentos feitos em paraísos fiscais exigem menos receita operacional para obter resultados mais altos. Barrios e D'Andria (2020) concluíram, após a análise de dados a nível mundial, que aqueles setores que realizam mais transferências de lucros reduziram seu custo 
médio de capital, e com isso atraíram mais investimentos quando comparados aos demais setores menos capazes de se esquivar dos impostos. Eles também concluíram que os ativos intangíveis se mostram relacionados à transferência de lucros devido à dificuldade de controle e fiscalização na contabilização desses ativos.

No intuito de mitigar a evasão fiscal, as autoridades fiscais aplicam o princípio do arm's length, que consiste na comparação dos preços utilizados nas transações entre partes relacionadas com os preços de mercado, assim verifica-se a adequabilidade do valor da renda comercial e dos royalties das multinacionais e detectam-se práticas abusivas de agressividade fiscal (Keuschnigg \& Devereux, 2013). Na Austrália, devido ao aumento de esquemas de planejamento tributário agressivo por parte das multinacionais, surgiu uma nova demanda da sociedade, que aumentou a pressão sobre os governos e os formuladores de políticas públicas, no sentido de coibir tais práticas (Oguttu \& Kayis-Kumar, 2020). Ainda com o propósito de mitigar a evasão de recursos, vários países propuseram regras de subcapitalização, regras que limitam a dedutibilidade dos juros sobre empréstimos internos e tem o intuito de evitar a transferência excessiva de lucros por parte de empresas multinacionais (Goyvaerts \& Roggeman, 2020). Mardan \& Stimmelmayr (2020) analisaram a competição fiscal entre países e concluíram que países que têm capacidade de receber transferências tendem a não baixar os impostos, mas países que ofertam pouca infraestrutura, por exemplo, podem baixar os impostos. O oposto também é verdadeiro, de modo em que se os custos de transferência de lucros forem baixos, o país envolvido não baixa o imposto. Merlo et al. (2020) estudaram dados de empresas de 172 países para verificar como as restrições à dedutibilidade fiscal do custo dos juros afetam as escolhas de localização das empresas multinacionais. As regras de pequena capitalização foram implementadas em alguns países para evitar que as multinacionais mudem sua base tributária em países com taxas de impostos mais baixas, e o resultado deste estudo foi que as escolhas de localização das empresas são consideradas negativas em países com restrições mais rígidas, ou seja, as empresas levam em consideração o custo de transferência.

No que se refere à mensuração da agressividade tributária em relação à diferença entre o lucro contábil e o lucro tributário, a literatura prévia sugere que existem diferenças entre esses tipos de lucros (Hanlon \& Heitzman, 2010), isso porque cada critério de lucro segue regras próprias para mensuração. 0 lucro contábil obedece aos Princípios Contábeis Geralmente Aceitos (GAAP), enquanto o lucro tributável obedece às determinações legais ou fiscais (Ferreira et al., 2012; Chen \& Dhaliwal, Trombley, 2012; Noga \& Schnader, 2013). No que se refere à mensuração da agressividade fiscal, leva-se em consideração o imposto pago em relação ao valor adicionado, essa proxy de agressividade traz uma perspectiva relativa à contribuição da empresa para a sociedade (Silva, 2016).

Neste estudo, foram utilizadas duas proxies de agressividade fiscal. A BTD, que é a diferença entre o lucro contábil e o lucro tributário divido pelo ativo total, ela foi escolhida pois é uma proxy robusta associada ao planejamento tributário, e pode ainda ser utilizada para identificar indícios de ilegalidades fiscais e riscos conhecidos ou não pela empresa, porém desconhecidos pelos usuários externos (Nossa \& Teixeira, 2018; Noga \& Schnader, 2013; Silva 2016). E comparativamente, foi utilizada a TTVA para mensurar o impacto do imposto pago em relação ao valor adicionado pela empresa (Silva, 2016).

Como fatores organizacionais, a literatura preliminar relaciona a agressividade fiscal com o tamanho das empresas, alavancagem, gastos com pesquisas e desenvolvimento, nível de lucratividade e nível de operação no exterior. Inclusive, trazem evidências de que as maiores empresas possuem, em média, menores custos com planejamento tributário, o que alavancaria seu grau de agressividade fiscal, pois as empresas estariam mais susceptíveis para a participação de acordos com preços agressivos (Benvignati, 1985; Slemrod, 2001; Bernard, Jensen, \& Schott, 2006; Conover \& Nichols, 2000; Silva, 2016). Rezende, Dalmácio \& Rathke (2018, p. 31) apresentam argumentos de que "um ambiente com alta carga tributária, complexidade das legislações tributárias e competição tributária, criada entre as unidades administrativas, torna-se um terreno fértil para as empresas desenvolverem práticas de planejamento tributário".

Também há evidências de que a rentabilidade das empresas esteja relacionada com a agressividade fiscal, pois as grandes empresas podem aproveitar as diferenças na rentabilidade entre as entidades locais e as demais entidades não locais, o que reduz ainda mais os custos com planejamento tributário, já que há indícios de que quanto maiores os lucros, menor a agressividade fiscal. (Benvignati, 1985; Jacob, 1996; Conover \&Nichols, 2000; Gupta \& Newberry, 1997).

Lawless et al. (2018) estudaram o afeito da taxa de imposto cobrada sobre as decisões de localização de subsidiárias multinacionais. Para o desenvolvimento do estudo, eles analisaram empresas estabelecidas em 26 países europeus durante 8 anos. Eles concluíram que há grandes variações na sensibilidade das empresas às alíquotas de impostos cobradas. Eles chamam a atenção para as empresas do setor financeiro, estas são duplamente mais sensíveis às mudanças das taxas de imposto quando comparadas às empresas de outros setores. Pieretti e Pulina (2020) analisaram inciativas destinadas a eliminar a transferência de lucros, concluíram que as empresas buscam ambientes com impostos mais baixos e inclusive, podem se transferir em busca de redução de tributos.

A estrutura de capital, por sua vez, também é outro fator organizacional que pode impactar na carga tributária efetiva das empresas, pois quanto mais alavancadas forem as empresas, maiores serão as oportunidades para aproveitamento das dedutibilidades trazidas pelos juros e taxas de empréstimos, o que também torna as empresas mais agressivas tributariamente (Gupta \& Newberry, 1997; Hines, 1996; Newberry 
\& Dhaliwal, 2001; Bernard et al., 2006; Dyreng et al., 2008; Pohlmann \& ludícibus, 2010; Santos, Cavalcante, \& Rodrigues, 2013; Blouin, Huizinga, Laeven \& Nicode`Me, 2014). Goyvaerts e Roggeman (2020) concluíram que vários países propuseram regras de subcapitalização que limitam a dedutibilidade dos juros sobre empréstimos internos, a fim de evitar a transferência excessiva de lucros por parte de empresas multinacionais.

Sobre a percepção do mercado sobre a agressividade tributária, Akhtar et al. (2019) concluíram que os preços das ações caem na janela do evento próximo a data do anúncio das informações financeiras, em outras palavras, no curto prazo, o mercado pune as empresas agressivas tributariamente, mas no longo prazo, as multinacionais não sofrem danos à reputação devido à evasão fiscal.

\subsection{Multinacionalidade e agressividade fiscal}

A literatura internacional sobre multinacionalidade relata que a tributação das empresas se torna mais complexas quando as empresas operam em diferentes países, devido à ausência de tratados internacionais específicos para regulação dos impostos corporativos e às diversas regras tributárias que as empresas estão sujeitas, e com isso, são geradas lacunas para a agressividade tributária (Zucman, 2014; Markusen, 1995; Oguttu \& Kayis-Kumar 2020; Choi et al., 2020; Goyvaerts \& Roggeman, 2020; Mardan \& Stimmelmayr, 2020, Merlo et al., 2020). Esses autores também discutem pontos acerca das vantagens, custos, mercados para a expansão dos negócios, e das vantagens e desvantagens para instalação das empresas em outros países.

As multinacionais são empresas que precisam se esforçar para gerenciar seus diversos canais e encontrar oportunidades para tornar suas operações mais lucrativas, o que por outro lado, as coloca sob o radar das autoridades fiscais, pois uma parte substancial do comércio internacional corresponde às vendas ou transações comerciais entre unidades da mesma empresa, dentro ou fora das fronteiras nacionais da matriz (Grewal, Saini, Kumar, Dwyer, \& Dahlstrom, 2018; Mehafdi, 2000; Choi et al., 2020).

Blouin (2012) sugere que quando as multinacionais atingem a maturidade (condição na qual as empresas possuem ganhos acumulados adequados para financiar seus investimentos), elas deslocam seu foco marginal de investimento e analisam se devem repatriar ou não os ganhos acumulados. As empresas multinacionais transferem lucros de países com impostos mais altos para países com impostos baixos ou com mais incentivos fiscais, na tentativa de reduzir seu passivo fiscal (Keuschnigg \& Devereux, 2013).

$\mathrm{Na}$ Austrália, devido ao aumento de esquemas de planejamento tributário agressivo por parte das multinacionais, surgiu uma nova demanda da sociedade, que aumentou a pressão sobre os governos e os formuladores de políticas públicas, no sentido de coibir a agressividade tributária (Oguttu \& Kayis-Kumar, 2020).

Mardan \& Stimmelmayr (2020) analisaram a competição fiscal entre países e concluíram que países que têm capacidade de receber transferências tendem a não baixar os impostos, mas países que ofertam pouca infraestrutura, por exemplo, podem baixar os impostos. Ou seja, os países de maior risco oferecem taxas de impostos mais baixas quando comparados aos países de menor risco. O oposto também é verdadeiro, de modo que se os custos de transferência de lucros forem baixos, o país envolvido não diminui o imposto. Merlo et al. (2020) estudaram dados de empresas de 172 países para verificar como as restrições à dedutibilidade fiscal do custo dos juros afetam as escolhas da localização das empresas multinacionais. As regras de pequena capitalização foram implementadas em alguns países para evitar que as multinacionais mudem sua base tributária para países com taxas de impostos mais baixas, e o resultado desse estudo mostra que as escolhas de localização das empresas são afetadas negativamente em países com restrições mais rígidos, ou seja, as empresas levam em consideração o custo de transferência.

Johannesen et al. (2020) analisaram dados de 210.000 corporações em 142 diferentes países para analisar se a evasão fiscal por empresas multinacionais é mais provável em países menos desenvolvidos. Eles concluem que a transferência de lucros está negativamente relacionada ao nível de desenvolvimento econômico e institucional, ou seja, em países em desenvolvimento é mais provável a transferência de lucros. Há ainda indícios de que a multinacionalidade tem relação direta com a agressividade fiscal, isso porque a arrecadação efetiva das empresas em seus países de origem pode diminuir em consequência do aumento da transferência de lucros para jurisdições com baixa tributação ou que possuem atrativos fiscais (Zucman, 2014; Taylor \& Richardson, 2015; Harvey, 2014; Blouin, 2012; Harvey, 2014, Keuschnigg \& Devereux, 2013). Registra-se ainda que ao efetuarem os reinvestimentos dos lucros em países estrangeiros, as empresas evitam a tributação dos ganhos no país de origem da matriz ou controlador, tornam-se mais agressivas tributariamente (Zucman, 2014; Taylor \& Richardson, 2015, Harvey, 2014; Blouin, 2012; Keuschnigg \& Devereux, 2013). Essa agressividade é utilizada como ferramenta estratégica no planejamento tributário, que depende do ambiente legal e de gestores das empresas convictos de que os benefícios gerados por essas estratégias (planejamentos tributários) são superiores aos custos de assumir tais práticas (Zucman, 2014; Taylor \& Richardson, 2015, Harvey, 2014; Blouin, 2012; Keuschnigg \& Devereux, 2013).

Por isso, a agressividade fiscal nas multinacionais pode ser associada a maior disponibilidade de recursos para aplicação em planejamento tributário, pois ao obterem lucros maiores do que as unidades domésticas em países com baixos impostos ou com incentivos fiscais, as empresas estrangeiras pagam tributos mais baixos em comparação aos pagos por empresas domésticas em países com alta tributação ou 
sem incentivos (Mehafdi, 2000; Slemrod, 2001; Smith, 2002; Bartelsman \& Beetsma, 2003; Baldenius, Melumad e Reichelstein, 2004; Hyde \& Choe, 2005; Egger, Eggert, \& Winner, 2010; Shunko, Debo \& Gavirneni, 2014; Barrios \& D'Andria, 2020).

Quanto à forma de identificação da multinacionalidade, Allayannis e Weston (2001) consideram apenas a diversificação geográfica das empresas para sua caracterização. Como nesta pesquisa, a multinacionalidade foi estudada em um contexto relacionado ao comércio internacional, que é uma abordagem mais atual introduzida por Markusen (1995), que considera a multinacionalidade representada pelo controle substancial exercido por uma empresa estrangeira, ou a existência de subsidiária em um país estrangeiro. Os termos "empresa multinacional" e "investimento estrangeiro direto" também foram utilizados como sinônimos nesta pesquisa, conforme sugerido por Markusen (1995).

Por se tratar o Brasil como um país em desenvolvimento e diante da literatura apresentada, apresenta-se a hipótese a ser testada:

$H_{1}$ : A agressividade fiscal aumenta sob a presença de multinacionalidade nas empresas do mercado brasileiro listadas na B3.

\subsection{Ativos intangíveis e a agressividade fiscal}

O ativo intangível das entidades é um fator economicamente relevante, isso pela sua alta subjetividade de mensuração e sua capacidade de gerar benefícios fiscais decorrentes do aproveitamento das amortizações (Oliveira \& Beuren, 2003; Perez \& Famá, 2006; Kaplan \& Norton, 2009; Taylor \& Richardson, 2015; Silva, 2016; Barrios e D'Andria, 2020). Os ativos intangíveis trazem vantagem competitiva para as organizações e podem ter relação direta com a agressividade fiscal das empresas (Oliveira \& Beuren, 2003, Perez \& Famá, 2006, Kaplan \& Norton, 2009, Taylor \& Richardson, 2015, Silva, 2016, Barrios e D'Andria, 2020).

Devido ao crescimento das transações que envolvem transferência de ativos intangíveis entre afiliados de um mesmo grupo empresarial, e às oportunidades de planejamento tributário trazidas pela dedutibilidade das amortizações, as autoridades locais começaram a observar mais de perto o cumprimento do princípio do arm's length, (respeito as regras tributárias) pelas empresas (Markham, 2005, \& Taylor \& Richardson, 2015). Barrios e D'Andria (2020) concluíram, após a análise de dados a nível mundial, que aqueles setores que realizam mais transferências de lucros reduzem seu custo médio de capital, com isso atraem mais investimentos quando comparados aos demais setores, que são menos capazes de se esquivar dos impostos. Eles também concluíram que os ativos intangíveis se mostram relacionados à transferência de lucros.

Os ativos intangíveis são itens organizacionais com valor de mercado próprio que contribuem para a geração de valor para empresas por um longo período. Desta forma, a sua amortização pode ocorrer de forma muito flexível, e com isso pode oportunizar a agressividade fiscal. Isto ocorre, dado que as empresas podem escolher dentre as várias formas alternativas de reconhecimento da amortização dos ativos intangíveis, e inclusive, pode reduzir o lucro, que é a base para a tributação (Ferreira et al., 2012; Taylor \& Richardson, 2015; Silva, 2016; Barrios \& D'Andria, 2020).

As práticas de planejamento tributário podem determinar quão agressivas as empresas podem ser, o quanto das estratégias de planejamento influenciarão no desempenho organizacional e no risco da descaracterização da legitimidade no reconhecimento, e consequentemente, na tributação desses itens, 0 que pode ocorrer pelas dificuldades na comprovação da dedutibilidade das elevadas amortizações (Silva, 2016; Perez \& Famá, 2006). Os ativos intangíveis podem auxiliar os gestores no gerenciamento de uma posição mais competitiva da entidade pela ausência de mercados bem estabelecidos, além da subjetividade desses itens a partir da exploração dos benefícios fiscais entre afiliados para o aproveitamento da dedutibilidade das amortizações, o que alavancaria os resultados organizacionais com impacto direto nos tributos sobre o lucro (Perez \& Famá, 2006; Kaplan \& Norton, 2009; Shackelford; Slemrod, Sallee, 2011; Dyreng, Hanlon, Maydew, 2008; Silva, 2016). Diante do exposto, apresenta-se a segunda hipótese de pesquisa: na B3.

$\mathrm{H}_{2}$ : quanto mais alto a ativo intangível mais alta a agressividade fiscal das empresas listadas

Taylor e Richardson (2015) estudaram empresas do mercado americano, e lá eles concluíram que quando a empresa é multinacional, na medida que aumentam os ativos intangíveis, aumentam a agressividade fiscal (agressividade dos preços de transferência). Para Silva (2016), os preços de transferências refletem algum grau de agressividade fiscal. Diante do exposto, apresenta-se a terceira hipótese:

$\mathrm{H}_{3}$ : No contexto de multinacionalidade, na medida que aumentam os ativos intangíveis aumenta a agressividade fiscal das empresas comparativamente às brasileiras listadas na B3 que não tem multinacionalidade. 


\section{Metodologia da Pesquisa}

\subsection{Modelo proposto}

Esta pesquisa caracteriza-se como empírica com a utilização de dados secundários, dos demonstrativos financeiros divulgados pelas empresas, sendo ainda uma pesquisa documental, quantitativa, descritiva que utilizou a técnica da análise de conteúdo para inferir acerca da multinacionalidade das empresas (Beuren et al., 2010; \& Bardin, 2004).

O objetivo deste estudo é verificar como a agressividade tributária (BTD ou TTVA) é afetada pela multinacionalidade considerando o nível de ativos intangíveis das empresas listadas na B3.

Para testar as hipóteses estabelecidas nesta pesquisa foi utilizado o modelo econométrico apresentado pela equação (1):

$$
\begin{aligned}
\operatorname{AGRESS}_{i t}=\beta_{0}+ & \beta_{1}\left(\text { DMULT }_{i t}\right)+\beta_{2}\left(\operatorname{INTANG}_{i t}\right)+\beta_{3}\left(\text { DMULT }_{i t} * \operatorname{INTANG}_{i t}\right) \\
& +\beta \text { CONTROLES }_{i t}
\end{aligned}
$$

Em que: $A G R E S S_{i t}$ representa uma das proxies utilizadas para medir agressividade fiscal da empresa $i$ no ano $t$. DMULT $i t$ representa a medida de multinacionalidade. INTANG $G_{i t}$ representa os ativos intangíveis da empresa $i$ no ano $t$. Por meio dos coeficientes $\beta_{1}, \beta_{2}$ e $\beta_{3}$ serão testadas as hipóteses de pesquisa $\mathrm{H} 1, \mathrm{H} 2$ e H3, respectivamente.

\subsection{Agressividade fiscal}

Para medir a agressividade fiscal foram utilizadas duas proxies: Book Tax Differences (BTD) (Frank et al., 2009) e a Taxa de Tributos de Valor Adicionado (TTVA) (Silva, 2016). A BTD é medida pela diferença entre o Lucro Contábil e o Lucro Real, em que o cálculo do Lucro Real é explicitado na Tabela 1, quando maior a BTD maior é a agressividade fiscal. A TTVA é medida pela razão entre a carga tributária utilizando os dados da Demonstração de Valor Adicionado (DVA) e o Valor Adicionado Total a Distribuir, sendo assim, quanto menor a TTVA maior é a agressividade fiscal.

TABELA 1:

LAIR e Lucro Real

\begin{tabular}{ccc}
\hline \multirow{2}{*}{ (1) } & \multicolumn{1}{c}{ Dados } & Descrição e Fonte de Coleta dos Dados \\
\cline { 2 - 3 } & Lucro Antes do IR (LAIR) & Valor da Conta dos Resultados Antes dos Tributos \\
(2) & Alíquotas do IR e CSLL & $\begin{array}{c}\text { Valor referente as alíquotas do IRPJ (25\% considerando as alíquotas } \\
\text { normal e adicional) mais 9\% referente a CSLL. No total será considerado } \\
34 \%\end{array}$ \\
\hline (3) & IR e CSLL corrente & $\begin{array}{c}\text { Valor das despesas com tributos sobre o lucro (IRPJ e CSLL) correntes, } \\
\text { disponível nas Demonstrações de Resultados (DR) Consolidadas }\end{array}$ \\
\hline (4) & IR e CSLL diferido & $\begin{array}{c}\text { Valor das despesas com tributos sobre o lucro (IRPJ e CSLL) diferidos } \\
\text { disponível nas Demonstrações de Resultados (DR) Consolidadas }\end{array}$ \\
\hline (5) & Lucro Real & $\begin{array}{c}\text { Valor obtido com a soma dos itens (3) e (4) dividido pelo item (2). Este } \\
\text { cálculo é uma aproximação do Lucro Real, pois essa informação não é } \\
\text { encontrada nos informes contábeis }\end{array}$ \\
\hline
\end{tabular}

Fonte: Tabela elaborada pelos autores.

\subsection{Multinacionalidade e intangíveis}

A Multinacionalidade (DMULT) foi mensurada a partir da definição trazida por Markusen (1995), é capturada por meio de 3 variáveis dummy: 1) DMULT_CONTR $R_{i t}$ assume o valor 1 se for identificado controle substancial de uma empresa estrangeira sobre a empresa $i$ no ano $t, 0$ caso contrário; 2) DMULT_SUBS $S_{i t}$ assume o valor 1 se a empresa $i$ possui subsidiária em país estrangeiro no ano $t, 0$ caso contrário; e 3 ) $D M U L T_{-} I N V E S T_{i t}$ assume o valor 1 se a empresa $i$ possui investimentos estrangeiros diretos no ano $t, 0$ caso contrário, sendo essa uma nova métrica para identificação da multinacionalidade, que poderá ser replicada em outras pesquisas sobre esta temática. De acordo com a hipótese $\mathrm{H} 1$, espera-se que os coeficientes destas três variáveis dummy seja positivo quando utilizando a proxy BTD, e negativo quanto utilizando a proxy TTVA. Indicando que a agressividade fiscal é maior, em média, na presença de multinacionalidade.

O nível dos ativos intangíveis foi mensurado pelo valor dos ativos intangíveis dividido pelo ativo total, como usado por Chen et al. (2010). De acordo com a hipótese H2, espera-se que o coeficiente da variável INTANG seja positivo quando utilizando a proxy BTD, e negativo quanto utilizando a proxy TTVA. Indicando que quanto maior o nível de ativos intangíveis, maior será a agressividade fiscal, em média.

Também foi verificado o efeito adicional da multinacionalidade na relação entre os intangíveis e a agressividade fiscal, por meio da interação entre as variáveis dummy de multinacionalidade (DMULT_CONTR, DMULT_SUBS e DMULT_INVEST) e a variável INTANG. De acordo com a hipótese H3, espera-se que o coeficiente da variável das interações seja positivo quando utilizando a proxy BTD, e negativo quanto 
utilizando a proxy TTVA. Indicando que na presença de multinacionalidade, a utilização dos ativos intangíveis para redução da carga tributária é ainda mais acentuada.

\subsection{Controles}

As variáveis de controle do modelo são: tamanho da empresa (TAM), rentabilidade (ROA) e alavancagem (ALAV). A variável (TAM) foi mensurada como o logaritmo natural do ativo total, seguindo Stickney e McGee (1982), para o qual espera-se que maiores empresas sejam mais agressivas tributariamente, pois os custos para o planejamento tributário poderiam ser rateados e distribuídos entre os membros do grupo empresarial. A variável de controle (ROA) foi mensurada, conforme Ramalho e Martinez (2014), como lucro operacional dividido pelo ativo total do ano anterior, se espera que empresas com maior rentabilidade tenham maiores níveis de agressividade fiscal, pois as empresas tenderiam a explorar as diferenças na rentabilidade dos membros locais e não locais (Benvignati, 1985; Jacob, 1996; Conover \& Nichols, 2000). A alavancagem (ALAV) foi medida pela razão da dívida de longo prazo pelo ativo total, conforme Gupta e Newberry (1997). Também se espera que a alavancagem tenha relação positiva com a agressividade fiscal da empresa.

A Tabela 2 apresenta a descrição de todas as variáveis do modelo, incluindo a fonte dos dados e as referências da literatura.

TABELA 2:

Variáveis do Modelo de Regressão

\begin{tabular}{|c|c|c|}
\hline Variáveis & Mensuração e Fonte de Coleta & Autores \\
\hline \multicolumn{3}{|l|}{ Variáveis Explicadas } \\
\hline BTD & $\begin{array}{l}\text { Mensurada pela razão entre a diferença do LAIR e o Lucro Real, e o Ativo } \\
\text { Total. Os dados para gerar a variável foram coletados da Economática®. }\end{array}$ & (Frank et al., 2009) \\
\hline TTVA & $\begin{array}{l}\text { Mensurada pela razão entre a carga tributária da DVA e o Valor Adicionado } \\
\text { Total a Distribuir. Os dados foram coletados do sítio da CVM. }\end{array}$ & Silva (2016) \\
\hline \multicolumn{3}{|c|}{ - } \\
\hline MULTI & $\begin{array}{l}\text { Variável dummy que assume o valor de } 1 \text { quando há controle substancial } \\
\text { por empresa estrangeira, subsidiária em um país estrangeiro ou } \\
\text { investimentos estrangeiros diretos e } 0 \text { caso contrário para a empresa i no } \\
\text { ano t. Os dados para gerar essa variável foram coletadas dos Formulários } \\
\text { de Referência disponíveis na B3 e nos sítios das empresas. }\end{array}$ & Markusen (1995) \\
\hline INTANG & $\begin{array}{l}\text { Mensurada pelo total de ativos intangíveis dividido pelo ativo total da } \\
\text { empresa i para o ano t. Dados para gerar essa variável foram coletados } \\
\text { da Economática®. }\end{array}$ & S.Chen et al. (2010) \\
\hline MULT* INTANG $^{*}$ & Mensurada pela interação das variáveis MULT INTANG. & Taylor et al. (2015) \\
\hline \multicolumn{3}{|l|}{ Variáveis de Controle } \\
\hline TAM & $\begin{array}{l}\text { Mensurada pelo logaritmo natural do ativo total. Dados para gerar essa } \\
\text { variável foram coletados da Economática } \AA \text {. }\end{array}$ & $\begin{array}{l}\text { Stickney e McGee } \\
\text { (1982) }\end{array}$ \\
\hline ROA & $\begin{array}{l}\text { Mensurada pela razão entre o lucro operacional e o ativo total do ano } \\
\text { anterior. Dados para gerar essa variável foram coletados da Economática®. }\end{array}$ & $\begin{array}{l}\text { Ramalho e Martinez } \\
\text { (2014) }\end{array}$ \\
\hline ALAV & $\begin{array}{l}\text { Mensurada pela razão entre a dívida de longo prazo e o ativo total. Dados } \\
\text { para gerar essa variável foram coletados da Economáticaß. }\end{array}$ & $\begin{array}{c}\text { Gupta e Newberry } \\
(1997)\end{array}$ \\
\hline
\end{tabular}

\subsection{Construção da base de dados}

O mercado de ações brasileiro é a população alvo desta pesquisa, da qual foram analisados os dados referentes ao período de 2010 a 2017 das empresas listadas na B3, sendo a escolha desse período decorrente da obrigatoriedade do envio dos formulários de referência (Instrução da Comissão de Valores Monetários - CVM no 480/2009) a partir de 2010 para as empresas listadas na B3 e o ano de 2017 o último período que contém as informações financeiras divulgadas pelas empresas. Foram excluídas da amostra as instituições financeiras e as empresas do setor de seguros, empresas com patrimônio líquido negativo e empresas/ano que não estavam disponíveis todas as informações necessárias para cálculo das variáveis do modelo proposto. Resultando em 888 observações empresa/ano de 2010 a 2017. Por fim, todas as variáveis foram winsorizadas à 1\%. A Tabela 3 exibe a quantidade de observações iniciais e a perda de observações em cada etapa.

TABELA 3:

Composição da Amostra

\begin{tabular}{lc}
\hline \multicolumn{1}{c}{ Descrição } & Quantidade \\
\hline Quantidade de Observações Iniciais & 5904 \\
(-) Exclusão das Empresas do setor financeiros e seguros & $(540)$ \\
(=) Total após a exclusão & 5364 \\
(-) Exclusão das Empresas com PL negativo & $(427)$ \\
(-) Exclusão de Empresas sem informação & $(4049)$ \\
(=) Quantidade de Observações Final da Amostra & 888 \\
\hline
\end{tabular}

Fonte: Tabela elaborada pelos autores. 


\section{Resultados da Pesquisa}

\subsection{Estatística descritiva}

A Tabela 4 apresenta a estatística descritiva das variáveis contínuas do modelo proposto, e a Tabela 5 apresenta a frequência das variáveis dummy do modelo.

TABELA 4:

Estatística Descritiva

\begin{tabular}{lcccccccc}
\hline Variáveis $^{\mathbf{a}}$ & $\mathbf{N}$ & MÍN & P25 & MÉDIA & MEDIANA & DP & P75 & MÁX \\
\hline BTD & 888 & $-3,0692$ & $-0,0095$ & $-0,0880$ & 0,0084 & 0,5014 & 0,0284 & 0,3278 \\
TTVA & 888 & 0,0043 & 0,1776 & 0,2856 & 0,2614 & 0,1901 & 0,3529 & 1,3625 \\
INTANG & 888 & 0,0000 & 0,0014 & 0,1194 & 0,0311 & 0,1942 & 0,1427 & 0,8011 \\
TAM & 888 & 3,7743 & 12,6428 & 13,7606 & 14,2430 & 2,7508 & 15,3436 & 18,7120 \\
ALAV & 888 & 0,0000 & 0,0063 & 0,1634 & 0,1382 & 0,1516 & 0,2714 & 0,5702 \\
ROA & 888 & $-0,0249$ & 0,0859 & 0,2373 & 0,1831 & 0,2055 & 0,3432 & 0,8399 \\
\hline
\end{tabular}

a BTD é a diferença entre o LAIR e o lucro real dividida pelo ativo total. TTVA é a razão entre a DVA e o valor adicionado total a distribuir. INTANGIVEL é a razão entre os ativos intangíveis e o ativo total. TAM é o logaritmo natural do ativo total. ALAVANCAGEM é a razão entre a dívida de longo prazo e o ativo total. ROA é a razão entre o lucro operacional e o ativo total do ano anterior.

Fonte: elaborada pelos autores.

A média BTD negativa indica que, em média, as empresas brasileiras desta amostra não são tributariamente agressivas. No que tange a variável TTVA a média de 0,2856 indica que as empresas da amostra estão suportando, em média, uma carga tributária de $28,56 \%$ sobre o valor adicionado a distribuir gerado pelas operações das empresas. A variável INTANG apresenta uma média de 0,1194 , indicando os ativos intangíveis representam $11,94 \%$ dos ativos totais das empresas da amostra, em média (Tabela4).

A Tabela 5 mostra a frequência percentual das empresas de cada grupo por quartis das proxies de agressividade fiscal, os quartis foram calculados por ano. Os quartis da variável BTD variam do menor nível de agressividade fiscal (quartil 1) ao maior nível de agressividade fiscal (quartil 4). Enquanto os quartis da variável TTVA variam do maior nível de agressividade fiscal (quartil 1) ao menor nível de agressividade fiscal (quartil 4).

TABELA 5:

Tabela de Frequência por Quartis

\begin{tabular}{|c|c|c|c|c|c|c|c|c|c|}
\hline & \multirow[b]{2}{*}{ GRUPO } & \multicolumn{4}{|c|}{ QUARTIS BTD } & \multicolumn{4}{|c|}{ QUARTIS TTVA } \\
\hline & & 1 & 2 & 3 & 4 & 1 & 2 & 3 & 4 \\
\hline \multirow{2}{*}{ DMULT_CONTR } & 1 & $13,76 \%$ & $20,18 \%$ & $35,78 \%$ & $30,28 \%$ & $23,85 \%$ & $27,52 \%$ & $22,02 \%$ & $26,61 \%$ \\
\hline & 0 & $26,96 \%$ & $25,55 \%$ & $23,49 \%$ & $24,01 \%$ & $25,55 \%$ & $24,52 \%$ & $25,42 \%$ & $24,52 \%$ \\
\hline \multirow{2}{*}{ DMULT_SUBS } & 1 & $21,11 \%$ & $20,56 \%$ & $30,00 \%$ & $28,33 \%$ & $21,67 \%$ & $30,00 \%$ & $32,78 \%$ & $15,56 \%$ \\
\hline & 0 & $26,41 \%$ & $25,99 \%$ & $23,73 \%$ & $23,87 \%$ & $26,27 \%$ & $23,59 \%$ & $23,02 \%$ & $27,12 \%$ \\
\hline \multirow[t]{2}{*}{ DMULT_INVEST } & 1 & $20,70 \%$ & $22,58 \%$ & $27,96 \%$ & $28,76 \%$ & $25,54 \%$ & $27,69 \%$ & $22,31 \%$ & $24,46 \%$ \\
\hline & 0 & $28,68 \%$ & $26,55 \%$ & $22,87 \%$ & $21,90 \%$ & $25,19 \%$ & $22,87 \%$ & $26,94 \%$ & $25,00 \%$ \\
\hline
\end{tabular}

Legenda: BTD: Quartil 1 (menor nível de agressividade fiscal) - Quartil 4 (maior nível de agressividade fiscal). TTVA: Quartil 1 (maior nível de agressividade fiscal) - Quartil 4 (menor nível de agressividade fiscal). OBS.: Os quartis foram calculados por ano.

Fonte: Tabela elaborada pelos autores.

De acordo com os dados apresentados na Tabela 5, as empresas que estão no contexto de nenhuma forma de multinacionalidade (DMULT_CONTR=0, DMULT_SUBS=0, DMULT_INVEST=0), estão distribuídas de maneira homogênea ao longo dos diferentes níveis de agressividade fiscal. As empresas que apresentam controle estrangeiro substancial (DMULT_SUBS $=1$ ) apresentam maior concentração nos $3^{\circ}$ e $4^{\circ}$ quartis da variável BTD (66,06\%), que são os níveis de maior agressividade fiscal. As empresas com subsidiárias no exterior também apresentam maior concentração nos $3^{\circ}$ e $4^{\circ}$ quartis da variável BTD (58,33\%), que são os níveis de maior agressividade fiscal.

A Tabela 6 apresenta a correlação de Pearson entre as variáveis contínuas do modelo. Nenhuma das variáveis independentes apresentou correlação alta entre si, descartando evidências de colinearidade perfeita no modelo. 
TABELA 6:

Correlação de Pearson

\begin{tabular}{|c|c|c|c|c|c|c|}
\hline Variáveis $^{a}$ & BTD & TTVA & INTANG & TAM & ALAV & ROA \\
\hline BTD & 1 & & & & & \\
\hline TTVA & 0,0340 & 1 & & & & \\
\hline INTANG & $0,1042^{\star \star *}$ & $-0,0350$ & 1 & & & \\
\hline TAM & $0,6988^{\star \star *}$ & $-0,1151^{\star \star *}$ & $0,2377^{\star \star *}$ & 1 & & \\
\hline ALAV & $0,1980^{* * *}$ & $-0,2233^{* * *}$ & $0,1244^{\star * *}$ & $0,4691^{* \star *}$ & 1 & \\
\hline $\mathrm{ROA}$ & $0,2556^{\star \star \star}$ & $0,1168^{\star * *}$ & $0,1204^{\star \star *}$ & $0,1524^{\star \star \star}$ & $-0,0920^{\star \star \star}$ & 1 \\
\hline
\end{tabular}

a BTD é a diferença entre o LAIR e o lucro real dividida pelo ativo total. TTVA é a razão entre a DVA e o valor adicionado total a distribuir. INTANG é a razão entre os ativos intangíveis e o ativo total. TAM é o logaritmo natural do ativo total. ALAV é a razão entre a dívida de longo prazo e o ativo total. ROA é a razão entre o lucro operacional e o ativo total do ano anterior.

${ }^{*},{ }^{* *},{ }^{* * *}$ Indicam o nível de significância $10 \%, 5 \%$ e $1 \%$, respectivamente.

Fonte: Tabela elaborada pelos autores.

As variáveis INTANG, TAM, ALAV e ROA possuem correlação positiva e significantemente diferente de zero, o que indica que empresas com mais ativos intangíveis, maiores, mais alavancadas e com melhores rentabilidade são mais agressivas fiscalmente (Tabela 6)

\subsection{Resultados}

A Tabela 7 mostra os resultados da estimação do modelo exposta na Eq. (1). A coluna (1) fornece os resultados utilizando BTD como proxy para a agressividade fiscal, e a coluna (2) fornece os resultados utilizando TTVA como proxy para a agressividade fiscal. O P-Valor do Teste de Hausman para ambos os modelos foram inferiores à $10 \%$, rejeitando a hipótese nula de que o método mais apropriado para a estimação do modelo seria o método de Efeitos Aleatórios. Portanto, ambos modelos foram estimados utilizando o método de Efeitos Fixos com correção a heterocedasticidade.

A variável DMULT_CONTR apresentou coeficiente estatisticamente insignificante (Estat. $t=-0,56$ ) quando usando a variável BTD como proxy para a agressividade fiscal. Porém, quando usando a proxy TTVA esta variável apresentou um coeficiente estimado positivo de 0,0737 e estatisticamente significante à $10 \%$ (Estat. $t=1,79$ ). $O$ que indica que empresas listadas na B3 que possuem controle estrangeiro substancial são, em média, menos agressivas fiscalmente do que as demais. O que vai de encontro à hipótese $\mathrm{H} 1$ de que empresas a agressividade fiscal aumenta na presença de multinacionalidade.

A variável DMULT_SUBS apresentou coeficiente estatisticamente insignificante quando utilizando a proxy TTVA. Por outro lado, o coeficiente estimado foi estatisticamente significante à $5 \%$ e negativo, quando utilizando a proxy BTD para a agressividade fiscal. Indicando que empresas listadas na B3 que possuem subsidiárias no exterior são menos agressivas do que as empresas listadas na B3 que não possuem subsidiárias no exterior, em média. O que, também, vai de encontro à hipótese H1.

Para o coeficiente estimado da variável DMULT_INVEST não foi encontrada significância estatística em nenhum dos dois modelos. Logo, não há evidências estatísticas de que empresas listadas na B3 com investimento estrangeiro direto sejam, em média, mais agressivas do que as demais. Não confirmando a hipótese H1. Em geral, as evidências indicam que a presença de multinacionalidade reduz a agressividade fiscal.

Com relação aos ativos intangíveis, a variável INTANG não foi estatisticamente significante quando utilizando a proxy TTVA, e apresentou significância estatística de 5\% quando utilizando a proxy BTD. Como o coeficiente estimado foi negativo e estatisticamente diferente de zero, quando usando a BTD, isso significa que para empresas brasileiras em que não há presença de multinacionalidade, maiores níveis de ativos intangíveis estão relacionados a menos níveis de agressividade fiscal. O que vai de encontro a hipótese $\mathrm{H} 2$ de que empresas com mais intangíveis são, em média, mais agressivas fiscalmente.

A interação DMULT_CONTR*INTANG apresentou coeficiente estatisticamente significante em ambos os modelos. O coeficiente aparece positivo quando a variável dependente é a BTD e negativo quando a variável dependente é a TTVA. Para o modelo da coluna (1) em que as variáveis INTANG e DMULT_CONTR*INTANG apresentaram significância estatística, executamos um teste sobre a soma dos coeficientes das variáveis INTANG e DMULT_CONTR*INTANG. A estatística F, para a hipótese nula $H_{0}: \beta_{2}+$ $\beta_{3}=0$, foi de 0,09 com P-Valor de 0,7699. Portanto não podemos rejeitar a hipótese de que a soma destes coeficientes seja nula. Logo, para empresas que não possuem controle estrangeiro substancial, a presença de mais ativos intangíveis gera menores níveis de agressividade fiscal. Porém, na presença de controle estrangeiro a relação entre os ativos intangíveis e a agressividade fiscal se anula (Tabela 7) 
TABELA 7:

Resultados

\begin{tabular}{|c|c|c|c|c|}
\hline \multirow{3}{*}{ Variáveis $^{c}$} & \multirow{2}{*}{\multicolumn{2}{|c|}{$\begin{array}{l}(1) \\
\text { BTD }^{a}\end{array}$}} & \multirow{2}{*}{\multicolumn{2}{|c|}{$\begin{array}{c}(2) \\
\text { TTVA }^{\mathrm{b}}\end{array}$}} \\
\hline & & & & \\
\hline & Coef. & Estat. t. & Coef. & Estat. t. \\
\hline DMULT CONTR & $-0,0215$ & $(-0,56)$ & 0,0734 & $(1,79)^{\star}$ \\
\hline DMULT_SUBS & $-0,0949$ & $(-2,37)^{\star *}$ & 0,2108 & $(1,89)^{*}$ \\
\hline DMULT_INVEST & $-0,0234$ & $(-1,41)$ & $-0,0181$ & $(-0,95)$ \\
\hline INTANG $\bar{G}$ & $-0,2924$ & $(-2,58)^{* *}$ & 0,0616 & $(0,44)$ \\
\hline DMULT CONTR*INTANG & 0,3575 & $(1,67)^{\star}$ & $-0,2758$ & $(-2,20)^{* *}$ \\
\hline DMULT SUBS*INTANG & 0,2639 & $(0,92)$ & $-0,2958$ & $(-1,55)$ \\
\hline DMULT_INVEST*INTANG & 0,0262 & $(0,54)$ & 0,0255 & $(0,43)$ \\
\hline TAM - & 0,1842 & $(3,54)^{\star * *}$ & $-0,0205$ & $(-1,20)$ \\
\hline ALAV & $-0,1841$ & $(-1,94)^{\star}$ & $-0,0504$ & $(-0,75)$ \\
\hline$R O A$ & 0,3185 & $(4,44)^{\star \star *}$ & $-0,1251$ & $(-1,39)$ \\
\hline № de Obs. & & 888 & & 888 \\
\hline Teste de Hausman $\left(x^{2}\right)$ & & 16,87 & & 23,73 \\
\hline Teste de Hausman (P-Valor) & & 0,0773 & & 0083 \\
\hline \multicolumn{5}{|c|}{ 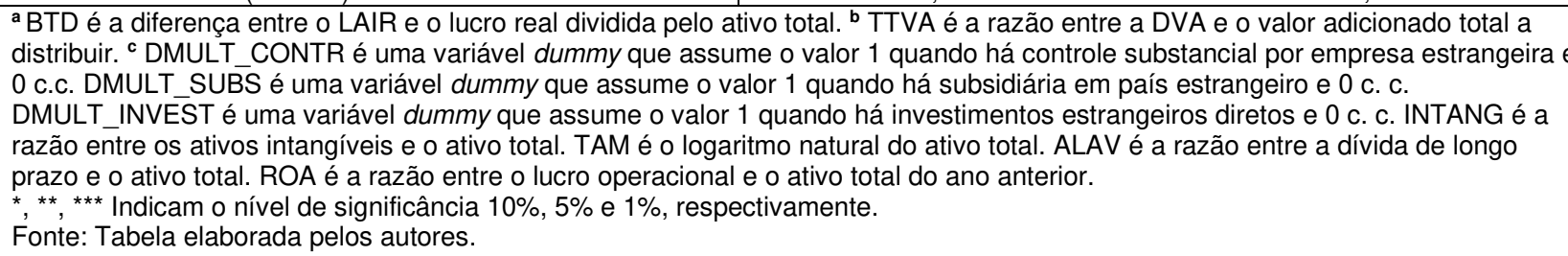 } \\
\hline
\end{tabular}

Para o modelo da coluna (2), utilizando a TTVA como proxy para agressividade fiscal, o coeficiente da variável INTANG foi estatisticamente insignificante, indicando que os intangíveis não afetam os níveis de agressividade fiscal, em média. Porém, o coeficiente da interação DMULT_CONTR*INTANG é negativo e estatisticamente significante à $5 \%$ (Coef $=-0,2758$ Estat. $t=-2,20)$, indicando que na presença de controle substancial estrangeiro, quanto maior o nível de ativos intangíveis maior é a agressividade fiscal, em média.

Em geral, as evidências encontradas indicam que a presença de multinacionalidade reduz, em média, os níveis de agressividade fiscal da empresa. Porém, quanto maior o nível de ativos intangíveis maior é a agressividade fiscal das empresas.

\section{Considerações Finais}

Este trabalho teve como objetivo analisar como a agressividade tributária (BTD ou TTVA) é afetada pela multinacionalidade considerando o nível de ativos intangíveis das empresas listadas na B3. Para atingir ao objetivo desta pesquisa foi desenvolvida uma pesquisa empírica na qual foram utilizados dados secundários dos demonstrativos financeiros divulgados pelas empresas, trata-se ainda de uma pesquisa documental, quantitativa, descritiva que se utilizou a técnica da análise de conteúdo para inferir acerca da multinacionalidade das empresas (Beuren et al., 2010; \& Bardin, 2004).

No que se refere às características da amostra analisada $12,27 \%$ das observações da amostra são de empresas que possuem controle estrangeiro substancial, $20,27 \%$ são de empresas que possuem subsidiária no exterior e $41,89 \%$ da amostra é composta por empresas que possuem investimento estrangeiro direto. Os resultados encontrados nesta pesquisa são de que empresas que estão no contexto de nenhuma forma de multinacionalidade estão organizadas de maneira homogênea quando olhamos para os níveis de agressividade fiscal. As empresas que apresentam controle estrangeiro substancial estão nos níveis mais altos de agressividade fiscal (BTD). As empresas com subsidiárias no exterior também apresentam maior concentração nos níveis de maior agressividade fiscal (BTD).

Ao olhar para o contexto no qual a empresa está sob o controle multinacional e na medida que aumenta o ativo intangível (DMULT_CONTR*INTANG) verificou-se resultado estatisticamente significante em ambos os modelos (BTD e TTVA). O coeficiente aparece positivo quando a variável dependente é a BTD e negativo quando a variável dependente é a TTVA, lembrando que na medida que aumenta a BTD isso significa agressividade fiscal e na medida que reduz a TTVA isso significa agressividade fiscal. No entanto, o teste desenvolvido a partir da estatística $\mathrm{F}$, para a hipótese nula $H_{0}: \beta_{2}+\beta_{3}=0$, foi de que não podemos rejeitar a hipótese de que a soma destes coeficientes seja nula. Diante do exposto, para empresas que não possuem controle estrangeiro substancial, a presença de mais ativos intangíveis gera menores níveis de agressividade fiscal. Porém, na presença de controle estrangeiro a relação entre os ativos intangíveis e a agressividade fiscal se anula.

Quando olhamos para a TTVA como proxy para agressividade fiscal, os intangíveis não afetam os níveis de agressividade fiscal, em média. Mas, DMULT_CONTR*INTANG mostra coeficiente negativo, indicando que na presença de controle substancial estrangeiro, quanto maior o nível de ativos intangíveis maior é a agressividade fiscal. Esses resultados corroboram aqueles encontrados por Taylor e Richardson (2015). Assim os resultados encontrados neste estudo são de que a presença de multinacionalidade reduz, em média, os níveis de agressividade fiscal da empresa. Porém, quanto maior o nível de ativos intangíveis 
maior é a agressividade fiscal das empresas.

Para futuras pesquisas recomenda-se a inclusão de outras variáveis como a utilização do prejuízo fiscal, dos benefícios fiscais locais, a fim de comparar os resultados encontrados, identificando apenas o efeito da agressividade fiscal nas empresas locais. Recomenda-se ainda a comparação dos efeitos da agressividade fiscais no cenário local com a agressividade encontrada em outros mercados para criação de perfis das empresas fiscalmente agressivas de forma mais global. Também se recomenda analisar a percepção do mercado sobre a agressividade tributária (Akhtar et al., 2019).

\section{Referências}

Allayannis, G., \& Weston, J. P. (2001). The use of foreign currency derivatives and firm market value. The Review of Financial Studies, 14(1), 243-276. doi: https://doi.org/10.1093/rfs/14.1.243

Akhtar S., Akhtar F., John K., \& Wong S.-W. (2019). Multinationals' tax evasion: A financial and governance perspective. Journal of Corporate Finance. 57, 35-62, Doi: https://doi.org/10.1016/j.jcorpfin.2017.11.009

Baldenius, T., Melumad, N. D., \& Reichelstein, S. (2004). Integrating managerial and tax objectives in transfer pricing. The Accounting Review, 79 (3), 591-615. doi: https://doi.org/10.2308/accr.2004.79.3.591

Bardin, L. (2004). Análise de conteúdo. 3ª . Lisboa: Edições, 70 (1), 223

Barrios S., \& D'Andria D. (2020). Profit Shifting and Industrial Heterogeneity. CESifo Economic Studies. 66(2), 134-156, doi: https://doi.org/10.1093/cesifo/ifz006

Bartelsman, E. J., \& Beetsma, R. M. (2000). Why pay more? Corporate tax avoidance through transfer pricing in OECD countries. Journal of Public Economics, 87 (9-10), 2225-2252. doi:

https://doi.org/10.1016/S0047-2727(02)00018-X

Beuren, I. M., et al. (2010). Como elaborar trabalhos monográficos em contabilidade. Editora Atlas SA.

Benvignati, A. M. (1985). An empirical investigation of international transfer pricing by US manufacturing firms. Multinationals and Transfer Pricing, 193-211.

Bernard, A. B., Jensen, J. B., \& Schott, P. K. (2006). Transfer pricing by US-based multinational firms. National Bureau of Economic Research. doi: https://doi.org/10.3386/w12493

Blouin, J. L. (2012). Taxation of multinational corporations. Foundations and Trends® in Accounting, 6 (1). doi: http://dx.doi.org/10.1561/1400000017

Blouin, J. L., Huizinga, H., Leaven, L., \& Nicodeme, G. J. A. (2014). Thin capitalization rules and multinational firm capital structure. International Monetary Fund, 2014. Recuperado em 15/02/2021 de https://www.imf.org/external/pubs/ft/wp/2014/wp1412.pdf

Cabello, O. G., \& Pereira, C. A. (2015). Efeitos das práticas de tributação do lucro na effective tax rate (ETR): uma abordagem da teoria das escolhas contábeis. Advances in Scientific and Applied Accounting, 8(3), 356-373, 2015. Doi: http://dx.doi.org/10.14392/asaa.2015080305

Chen, L. H., Dhaliwal, D.S., \& Trombley, M. A. (2012). Consistency of book-tax differences and the information content of earnings. Journal of the American Taxation Association, 34(2), 93-116. Doi: https://doi.org/10.2308/atax-50174

Chen, S., Chen, X., Cheng, Q, \& Shevlien, T. (2010). Are family firms more tax aggressive than non-family firms? Journal of Financial Economics, 95(1), 41-61. doi: https://doi.org/10.1016/j.jfineco.2009.02.003

Choi J.P., Furusawa T., \& Ishikawa J. (2020). Transfer pricing regulation and tax competition. Journal of International Economics. 127. Doi: https://doi.org/10.1016/j.jinteco.2020.103367

Colbert, G. J. S., \& Barry H. (1995). A multi-case investigation of a theory of the transfer pricing process. Accounting, Organizations and Society, 20(6), 423-456. doi: https://doi.org/10.1016/03613682(95)00007

Conover, T.L., \& Nichols, N. B. A. (2000). further examination of income shifting through transfer pricing considering firm size and/or distress. The International Journal of Accounting, 35 (2), 189-211. doi: 


\section{https://doi.org/10.1016/S0020-7063(00)00045-5}

Drake, K. D. (2015). Does firm life cycle inform the relation between book-tax differences and earnings persistence?. Social Science Research Network. Disponível em:

https://papers.ssrn.com/sol3/papers.cfm?abstract_id=2547778. Acesso em: 20 jun. 2019.

Dyreng, Scott D., Hanlon, Michelle, \& Maydew, Edward L. (2008). Long-run corporate tax avoidance. The Accounting Review, 83 (1), 61-82. Recuperado em 16/02/2021 de https://www.jstor.org/stable/30243511?seq=1

Eccles, Robert G. (1985). The transfer pricing problem: A theory for practice. Lexington Books, Lexington, MA.

Egger, P., Eggert, W., \& Winner, H. (2010). Saving taxes through foreign plant ownership. Journal of International Economics, 81(1), 99-108. doi: https://doi.org/10.1016/j.jinteco.2009.12.004

Emmanuel, Clive; Mehafdi, Messaoud. (1994). Transfer pricing. Academic Press and CIMA, London.

Ferreira, F.R., Martinez, A. L., Costa, F. M., \& Passamani, R. R. (2012). Book-tax differences y gestión de resultados en el mercado de acciones de Brasil. Revista de Administração de Empresas, 52(5) 488-501, 2012. doi: https://doi.org/10.1590/S0034-75902012000500002

Fonseca, K. B. C., \& Costa, P. S. (2017). Fatores determinantes das book-tax differences. Revista de Contabilidade e Organizações, 11 (29), 17-29, 2017. DOI: http://dx.doi.org/10.11606/rco.v11i29.122331

Frank, M. M., Lynch, L. J., \& Rego, S. O. (2009). Tax Reporting Aggressiveness and Its Relation to Aggressive Financial Reporting. The Accounting Review, 84(2), pp. 467-496. doi:

https://doi.org/10.2308/accr.2009.84.2.467

Goyvaerts D., \& Roggeman A. (2020). The Impact of Thin Capitalization Rules on Subsidiary Financing: Evidence from Belgium. Economist (Netherlands). 168(1), 23-51.

Grewal, R., Saini, A., Kumar, A., Dwyer, R. F., \& Dahlstrom, R. (2018). Marketing channel management by multinational corporations in foreign markets. Journal of Marketing, 82, (4), 49-69. Doi:

https://doi.org/10.1509/jm.16.0335.

Gupta, Sanjay, \& Newberry, Kaye. (1997). Determinants of the variability in corporate effective tax rates:

Evidence from longitudinal data. Journal of Accounting and Public Policy, 16 (1), 1-34, 1997. doi:

https://doi.org/10.1016/S0278-4254(96)00055-5

Hamamura, Jumpei. (2018). The impact of an information linkage system on a firm's organization structure, transfer price, and profit. Asia-Pacific Management Accounting Journal, 13 (1), 131-152.

Hanlon, Michelle, \& Heitzman, Shane. (2010). A review of tax research. Journal of accounting and Economics, 50(2-3), 127-178. Doi: https://doi.org/10.1016/j.jacceco.2010.09.002

Harvey, J. R. (2014). Corporate tax aggressiveness-recent history and policy options. National Tax Journal, 67(4).

Hines JR, \& James R. (1996). Tax policy and the activities of multinational corporations. National Bureau of Economic Research. Disponível em: www.nber.org/papers/w5589. Acesso em: 21 set. 2018.

Hyde, C. E., \& Choe, C. (2005). Keeping two sets of books: The relationship between tax and incentive transfer prices. Journal of Economics \& Management Strategy, 14 (1), 165-186. doi:

https://doi.org/10.1111/j.1430-9134.2005.00038.x

Instrução Normativa CVM n. 480, de 07 de dezembro de 2009. (2009). Dispõe sobre o registro de emissores de valores mobiliários admitidos à negociação em mercados regulamentados de valores mobiliários.

Disponível em: http://www.cvm.gov.br/legislacao/instrucoes/inst480.html.

Jacob, J. (1996). Taxes and transfer pricing: Income shifting and the volume of intrafirm transfers. Journal of Accounting Research, 34 (2), 301-312. doi: https://doi.org/10.2307/2491504 
Johannesen N., Torslov T., \& Wier L. (2020). Are Less Developed Countries More Exposed to Multinational Tax Avoidance? Method and Evidence from Micro-Data. Journal of Development Economics, 146, DOI: https://doi.org/10.1016/j.jdeveco.2020.102491

Kaplan, R. S., \& Norton, D. P. (2009). Measuring the strategic readiness of intangible assets. Harvard business review, 82(2), 52-63. Disponível em:

http://web.b.ebscohost.com/ehost/pdfviewer/pdfviewer?vid=3\&sid=0871c7e8-50e6-46e3-a192-

8e78be2157cb\%40sessionmgr103. Acesso em: 30 jun. 2018.

Keuschnigg, C., \& Devereux, M. P. (2013). The arm's length principle and distortions to multinational firm organization. Journal of International Economics, 89 (2), 432-440.

Lawless M., McCoy D., Morgenroth E.L.W., \& O"Toole C. M. (2018). Corporate tax and location choice for multinational firms. Applied Economics, 50(26), 2920-2031. Doi:

https://doi.org/10.1080/00036846.2017.1412078

Maluf, L.A. F. França, \& Asano, Jéssica T. (2019). Comparison of VaR Models to the Brazilian Stock Market Under the Hypothesis of Serial Independence in Higher Orders: Are Garch Models Really Indispensable? BBR. Brazilian Business Review, 16(6), 626-645. doi: https://doi.org/10.15728/bbr.2019.16.6.6.

Mardan M., \& Stimmelmayr M. (2020). Tax competition between developed, emerging, and developing countries - Same same but different? Journal of Development Economics, 146. Doi: https://doi.org/10.1016/j.jdeveco.2020.102491

Markham, Michelle A. (2005). Tax in a changing world: The transfer pricing of intangible assets. Tax Notes International, 40(10), 895-906.

Markusen, James R. (1995). The boundaries of multinational enterprises and the theory of international trade. Journal of Economic perspectives, 9 (2), 169-189. Recuperado em 16/02/2021 de https://pubs.aeaweb.org/doi/pdf/10.1257/jep.9.2.169

Martinez, A.L., \& Dalfior, M. D. (2015). Agressividade fiscal entre companhias controladoras e controladas. Revista da Receita Federal. Estudos tributários e aduaneiros, 2 (1), 344-362.

Mehafdi, M. (2000). The ethics of international transfer pricing. Journal of Business Ethics, 28 (4), 365-381, recuperado em 16/02/2021 de https://www.jstor.org/stable/25074427?seq=1

Merlo V., Riedel N., \& Wamser G. (2020). The impact of thin-capitalization rules on the location of multinational firms' foreign affiliates. Review of International Economics. 28(1), 35-61. Doi:

https://doi.org/10.1111/roie.12440

Minnick, K., \& Noga, T. (2010). Do corporate governance characteristics influence tax management? Journal of Corporate Finance, 16(5), 703-718, 2010.

Nerudova D., Solilova V., Litzman M., \& Janský P. (2020). International tax planning within the structure of corporate entities owned by the shareholder-individuals through Panama Papers destinations. Development Policy Review, 38(1), 124-139, Doi: https://doi.org/10.1111/dpr.12403

Newberry, K. J., \& Dhaliwal, D.S. (2001). Cross-jurisdictional income shifting by US multinationals: Evidence from international bond offerings. Journal of Accounting Research, 39 (3), 643-662. Recuperado em 16/02/2021 de https://www.jstor.org/stable/2672979?seq=1

Noga, T. J., \& Schnader, A. L. (2013). Book-tax differences as an indicator of financial distress. Accounting Horizons, 27 (3), 469-489, 2013. Doi: https://doi.org/10.2308/acch-504812013pp.

Nossa, V., \& Teixeira, J.C. (2018). Book-tax differences como indicador de previsão de insolvência. Anais Enanpad.

Oliveira, J. M., \& Beuren, I. M. (2003). O tratamento contábil do capital intelectual em empresas com valor de mercado superior ao valor contábil. Revista Contabilidade \& Finanças, 14 (32), 81-98. doi:

https://doi.org/10.1590/S1519-70772003000200006 
Oguttu A.W., \& Kayis-Kumar A. (2020). Curtailing aggressive tax planning: The case for introducing mandatory disclosure rules in Australia (part 1). eJournal of Tax Research, 17 (1), 83-104.

Perez, M.M., \& Famá, R. (2006). Ativos intangíveis e o desempenho empresarial. Revista Contabilidade \& Finanças, 17(40), 7-24. Doi: https://doi.org/10.1590/S1519-70772006000100002

Picciotto, S. (2018). International tax, regulatory arbitrage and the growth of transnational corporations. Transnational Corporations, 25(3), 27-53.

Pohlmann, M. C., \& ludícibus, S. (2010). Relação entre a tributação do lucro e a estrutura de capital das grandes empresas no Brasil. Revista Contabilidade \& Finanças, 21(53), 1-25. doi: https://doi.org/10.1590/S1519-70772010000200002

Ramalho, G. C., \& Martinez, A. L. (2014) Empresas Familiares Brasileiras e a Agressividade Fiscal. Anais do Congresso USP de Controladoria e Contabilidade. Disponível em: https://www.congressousp.fipecafi.org. Acesso em: 20 nov. 2018.

Ramos, M. C., \& Martinez, A. L. (2018). Agressividade Tributária e o Refazimento das Demonstrações Financeiras nas empresas brasileiras listadas na B3. Pensar Contábil, 20 (72). Recuperado em 16/02/2021 de http://www.spell.org.br/documentos/ver/51210/agressividade-tributaria-e-o-refazimento-dasdemonstracoes-financeiras-nas-empresas-brasileiras-listadas-na-b3-

Rezende, A. J., Dalmácio, F. Z., \& Rathke, A.A. T. (2018). Avaliação do impacto dos incentivos fiscais sobre os retornos e as políticas de investimento e financiamento das empresas. Revista Universo Contábil, 14(4), 28-49, 2018. doi: https://doi.org/10.4270/ruc.2018426

Rodrigues, R. M.R C., Melo, C. L. L., \& Paulo, E. (2019). Earnings management and quarterly discretionary accruals level in the Brazilian stock market. BBR. Brazilian Business Review, 16(3), 297-314. Doi: https://doi.org/10.15728/bbr.2019.16.3.6

Santos, M. A. C., Cavalcante, P., \& Rodrigues, R.N. (2013). Tamanho da firma e outros determinantes da tributação efetiva sobre o lucro no Brasil. Advances in Scientific and Applied Accounting, 6 (2), 179-210. https://asaa.anpcont.org.br/index.php/asaa/article/view/119

Shackelford, D. A., Slemrod, J., \& Sallee, J. M. (2011). A unifying model of how the tax system and generally accepted accounting principles affect corporate behavior. International Tax and Public Finance, 18(4), 461494, disponível em: http://ssrn.com/abstract=1686036. Acesso em: 07 jun. 2019.

Schanz D., Dinkel A., \& Keller S. (2017). Tax attractiveness and the location of German-controlled subsidiaries. Review of Managerial Science, 11(1), 251-297. Doi: https://doi.org/10.1007/s11846-016-0190-3

Shunko, M., Debo, L., \& Gavirneni, S. (2014). Transfer pricing and sourcing strategies for multinational firms. Production and Operations Management, 23(12) 12, 2043-2057.

Silva, R. F., \& Martinez, A. L. (2016). Agressividade fiscal e o custo de capital de terceiros no Brasil. Anais do Encontro da ANPAD, 40., Costa do Sauipe, BA.

Silva, J. M. (2016). A influência do ciclo de vida organizacional sobre o nível de planejamento tributário. Tese apresentada ao programa de pós-graduação em controladoria e contabilidade da faculdade de economia, administração e contabilidade de Ribeirão Preto da Universidade de São Paulo FEA-RP/USP.

Slemrod, J. (2001). A general model of the behavioral response to taxation. International Tax and Public Finance, 8 (2), 119-128. doi: https://doi.org/10.1023/A:1011204301325

Smith, M. (2002). Tax and incentive trade-offs in multinational transfer pricing. Journal of Accounting, Auditing \& Finance, 17(3), 209-236. doi: https://doi.org/10.1177/0148558X0201700302

Stickney, C. P., \& Mcgee, V. E. (1982). Effective corporate tax rates the effect of size, capital intensity, leverage, and other factors. Journal of Accounting and Public Policy, 1(2), 125-152. doi: https://doi.org/10.1016/S0278-4254(82)80004-5

Taylor, G., \& Richardson, L. R. (2015). Multinationality, tax havens, intangible assets, and transfer pricing aggressiveness: An empirical analysis. Journal of International Accounting Research, 14(1), 25-57. 
DOI: https://doi.org/10.2308/jiar-51019

Zucman, G. (2014). Taxing across borders: Tracking personal wealth and corporate profits. Journal of Economic Perspectives, 28(4), 121-48. DOI: http://dx.doi.org/10.1257/jep.28.4.121

\title{
NOTAS
}

\section{AGRADECIMENTOS}

Não se aplica.

\section{CONTRIBUIÇÃO DE AUTORIA}

Concepção e elaboração do manuscrito: A. P. A. Lima, S. N. Nossa, N. C. Moreira, Nossa, V.

Coleta de dados: A. P. A. Lima, S. N. Nossa, N. C. Moreira, Nossa, V.

Análise de dados: A. P. A. Lima, S. N. Nossa, N. C. Moreira, Nossa, V.

Discussão dos resultados: S. N. Nossa, N. C. Moreira, Nossa, V.

Revisão e aprovação: S N. Nossa, N. C. Moreira, Nossa, V.

\section{CONJUNTO DE DADOS DE PESQUISA}

Todo o conjunto de dados que dá suporte aos resultados deste estudo foi publicado no próprio artigo.

\section{FINANCIAMENTO}

Não se aplica.

\section{CONSENTIMENTO DE USO DE IMAGEM}

Não se aplica.

\section{APROVAÇÃO DE COMITÊ DE ÉTICA EM PESQUISA}

\author{
Não se aplica.
}

\section{CONFLITO DE INTERESSES}

Não se aplica.

\section{LICENÇA DE USO}

Os Direitos Autorais para artigos publicados neste periódico são do autor, com direitos de primeira publicação para a Revista. Em virtude de aparecerem nesta Revista de acesso público, os artigos são de uso gratuito, com atribuições próprias, em aplicações educacionais, de exercício profissional e para gestão pública. A Revista adotou a licença Creative Commons Atribuição 4.0 Internacional - CC BY NC ND. Esta licença permite acessar, baixar (download), copiar, imprimir, compartilhar, reutilizar e distribuir os artigos desde que com a citação da fonte, atribuindo os devidos créditos de autoria. Nesses casos, nenhuma permissão é necessária por parte dos autores ou dos editores. Autores têm autorização para assumir contratos adicionais separadamente, para distribuição não-exclusiva da versão do trabalho publicada nesta revista (ex.: publicar em repositório institucional ou um capítulo de livro).

\section{PUBLISHER}

Universidade Federal de Santa Catarina. Curso de Ciências Contábeis e Programa de Pós-graduação em Contabilidade. Publicação no Portal de Periódicos UFSC. As ideias expressadas neste artigo são de responsabilidade de seus autores, não representando, necessariamente, a opinião dos editores ou da universidade.

\section{EDITORES}

Carlos Eduardo Facin Lavarda e Suliani Rover

\section{HISTÓRICO}

Recebido em: 20/08/2020 - Revisado por pares em: 23/12/2020 - Reformulado em: 26/02/2021 Recomendado para publicação em: 02/03/2021 - Publicado em: 22/03/2021 